\title{
Case Based Metabolic Unit (CBMU): A Model for Better Understanding of Metabolic Pathways in the Second Year Extended Modular Program Medical Students
}

\author{
Unidade Metabólica Baseada em Casos (CBMU): Um modelo para melhor compreensão do metabolismo \\ no segundo ano do programa modular extendido de estudantes de medicina
}

\author{
Sanaa Eissa ${ }^{1 *}$, Ali Sabbour ${ }^{2}$ \\ ${ }^{1}$ Medical Biochemistry Department, Faculty of Medicine, Ain Shams University, Egypty \\ ${ }^{2}$ Vascular Surgery Department, Faculty of Medicine, Ain Shams University, Egypty \\ *e-mail:drsanaa_mohamed@med.asu.edu.eg
}

\begin{abstract}
We designed a case based metabolic unit (CBMU) which is a hybrid learning model using case based learning and interactive lectures for 2nd year EMP medical students ( $\mathrm{n}: 113)$ who firstly attended blood module (Classical model in learning metabolism) and then locomotor module (CBMU). At the end of both modules, they were evaluated through MCQ exams and the results of both exams were compared. The Majority of students (97-100\%) opined that case based metabolic unit learning model was interesting, motivating, and better than the classical model in understanding metabolic pathways and making learning stick. $99 \%$ of them demanded the application of this learning model in future biochemistry courses. Improvement in student's exam scores ensures that they grasped the knowledge by this model. In conclusion, CBMU is a useful learning tool for metabolic pathways using human cases to aid in connecting theory to practice which is positively reflected on student's academic performance.
\end{abstract}

Keywords: learning, CBL, modules

\begin{abstract}
Resumo
Projetamos uma unidade metabólicas baseada em casos (CBMU), o qual consiste em um modelo de aprendizagem híbrido usando aprendisagem baseada em caso e aulas interativas para estudantes do segundo ano de medicina ( $\mathrm{n}: 113$ ) que realizaram o módulo "sangue" (modelo clássico de aprendizagem de metabolismo) e do módulo lomomotor (CBMU). Ao final de ambos módulos, avaliamos os estudantes por meio do exame MCQ e comparamos os resultados de ambos exames. A maioria dos estudantes (97-100\%) opinaram que o modelo de aprendizagem baseada em casos da unidade metabólica foi interessante, moticadora e melhor que o modelo clássico na compreensão das vias metabólicas e tornando a aprendizagem efetiva. $99 \%$ dos respondentes demandaram a aplicação deste modelo de aprendizagem em futuros cursos de Bioquímica. A melhoria nas pontuações nas provas pelos estudantes assegura que eles obtiveram o conhecimento por meio deste modelo. Em conclusão, CBMU é uma ferramenta útil par aprendizagem das vias metabólicas usando casos humanos para auxiliar na conexão de teoria com a prática que é positivamente refletida no desempenho acadêmico dos estudates.
\end{abstract}

Palavras-chave: Aprendizagem, CBL, módulos 
Case Based Metabolic Unit (CBMU): A Model for Better Understanding of Metabolic Pathways in the Second Year Extended Modular Program Medical Students

\section{Record activity performed}

\begin{tabular}{|c|c|}
\hline Title & $\begin{array}{l}\text { Case based metabolic unit (CBMU): A model for better understanding of } \\
\text { metabolic pathways in the second year extended modular program medical } \\
\text { students }\end{array}$ \\
\hline $\begin{array}{l}\text { Target } \\
\text { audience }\end{array}$ & Medical students in the first three years \\
\hline $\begin{array}{l}\text { Related } \\
\text { disciplines }\end{array}$ & Medical biochemistry \\
\hline $\begin{array}{l}\text { Educational } \\
\text { objectives }\end{array}$ & $\begin{array}{l}\text { 1-to link metabolic concepts to clinical practice } \\
\text { 2- to build up a systematic and investigative thinking abilities of students early in } \\
\text { their learning to be able to apply what they learned to solve real-world problems }\end{array}$ \\
\hline $\begin{array}{l}\text { Justification of } \\
\text { use }\end{array}$ & Students questionnaires, exam results \\
\hline $\begin{array}{l}\text { Worked } \\
\text { contents }\end{array}$ & $\begin{array}{l}\text { Metabolic pathways relevant to locomotor module (glycogen metabolism, Fatty } \\
\text { acid oxidation) }\end{array}$ \\
\hline $\begin{array}{l}\text { Estimated } \\
\text { duration }\end{array}$ & $\begin{array}{l}\text { During the whole locomotor module from 9th November } 2015 \text { to } 10 \text { th January } \\
2016\end{array}$ \\
\hline Materials used & Printed clinical cases with investigative results, questionnaires, MCQ exams \\
\hline
\end{tabular}




\section{Introdution}

The progress of biochemistry and medicine are inseparable, and most of modern medicine would not be applied, as they are nowadays, with no understanding of the biochemical and molecular mechanism of human diseases. Thus, the significance of educating medical biochemistry is evident. Paradoxically, biochemistry for a lot of medical students is like lyrics in a foreign language, to be memorized but with no feeling.

They may not realize the importance of biochemistry until they have graduated and gone to practice. By that time, they have already forgotten what they learned, which compromises their professional competence [1-3]. In traditional biochemistry courses students would typically endure lectures where the teacher would demonstrate numerous biochemical pathways and reactions.

A skilled medical expert needs to be capable of going further than just accumulating a huge mass of information. It is essential for future doctors to build up a systematic and investigative thinking abilities early in their learning to be able to apply what they learned to solve real-world problems [4]. Integrated teaching is an important strategy for promoting effective learning and for making it easily saved by students. Many approaches are available for integrating the basic and clinical disciplines but fears are expressed that biochemistry would lose continuity in the integrated system.

EMP (extended modular program) is a new MBBS (Bachelor of Medicine, Bachelor of Surgery) program at the faculty of medicine, Ain Shams University in Egypt, which followed an integrated curriculum. All basic science introductory courses are taught in the first year followed by their reintroduction in the next two years in an integrated system based approach comprising 8 modules (blood, locomotor, respiratory, cardiovascular, C.N.S, special sense, endocrine, GIT\& liver, Genitourinary). Biochemistry course in the blood module ( $2^{\text {nd }}$ year $1^{\text {st }}$ module), was taught by the conventional approach to describing the concepts of the metabolic pathways as a continuous topic and at the end we draw round how a fault in this pathway would result in a disease.

Applying this classical approach, make biochemistry integration of lower impact. While biochemistry would be a harmonizing partner in the integration, if the metabolic unit is based on clinical cases relevant to the module. The cases will be analyzed to explain what would happen if something goes wrong in a particular reaction in the metabolic pathway and why and when it goes haywire. To achieve this goal, we designed a case based metabolic unit in the locomotor module for $2^{\text {nd }}$ year EMP medical students and we evaluated the impact of this learning approach on student's perception and performance in 
Case Based Metabolic Unit (CBMU): A Model for Better Understanding of Metabolic Pathways in the Second Year Extended Modular Program Medical Students

comparison with the conventional approach of learning metabolism in another module for the same students.

\section{Methodology}

The study was conducted on EMP second year medical students. Metabolic pathways in the blood module (from 28th September 2015 to 7th November 2015) were studied by the conventional approach applying different instruction methods e.g structured lectures and small group interactive sessions. In the 2nd module, locomotor module (from 9th November 2015 to 10th January 2016), the metabolic pathways were studied by the case based metabolic unit model.

The proposed approach was approved by the medical education council of the EMP program and the ethical committee. The metabolic pathways relevant to the locomotor module were presented in the lecture classes and small group discussion (SGD) sessions with clearly defined, short clinical problems consisting of symptoms and investigative data that were related to these topics [4].

The case (Appendix A) was presented at the start of a metabolic pathway unit with the symptoms of a particular metabolic disorder of muscle, which were made very clear. Students were asked to define, and to summarize the symptoms and the significant investigation findings of the case. Subsequently, the students were provided with the particular learning objectives (Appendix B). The lecturer was explaining the normal metabolic pathway and assisting the students through the facts and engaging them in understanding the pathway to find a possible solution to the problem and to answer all the learning objectives. Finally, the students were asked to analyze the medical problem to integrate the information and link the basics of biochemistry to the medical problem.

Students were also encouraged to ask questions during the lectures and SGD. Four clinical cases were used for this study to cover metabolic pathways integrated in the locomotor module. At the end of the module, students were requested to reply to a 9-item, 5-point Likert scale questionnaire concerning their perception of the utility of this case based metabolic unit model in learning metabolic pathways (Appendix $\mathrm{C}$ ). The questionnaire was prepared according to standard procedures [5] and evaluated the next items: better understanding of the metabolic pathways, the significance of the cases, chances for interaction and thinking, relevance for clinical practice, unit presentation organization and preparation, with one open-ended question at the end of the questionnaire. 
Case Based Metabolic Unit (CBMU): A Model for Better Understanding of Metabolic Pathways in the Second Year Extended Modular Program Medical Students

\section{Results}

There was a statistically significant $(p<0.007)$ increase in the test score of the academic performance of students in the locomotor module as compared to the blood module (Table 1 and Figure 1).

Table 1. Comparison of students scores in the evaluated modules.

\begin{tabular}{|c|c|c|}
\hline & Locomotor module & Blood module \\
\hline Mean scores & $\mathbf{8 0 . 2 \%}$ & $\mathbf{8 5 \%}$ \\
\hline SD & 17.31 & 13.92 \\
\hline t & \multicolumn{2}{|c|}{2.4} \\
\hline p & \multicolumn{2}{|c|}{$<0.007$} \\
\hline
\end{tabular}

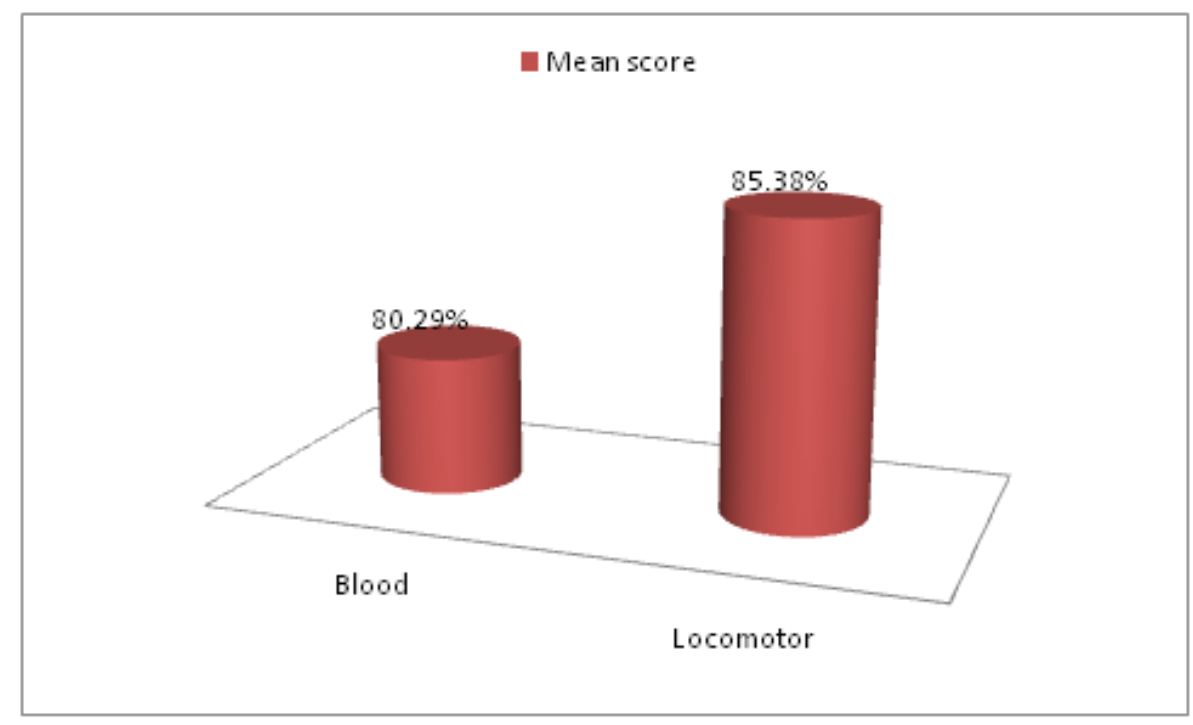

Figure 1. Students mean test scores in locomotor module compared to blood module.

Mean values and multiple bar diagram of the student responses have been shown in Table 2 and Figure 2.

Table 2. Results of student questionnaire (scale from 0 to 4 )

\begin{tabular}{|l|l|l|l|l|l|l|l|l|l|}
\hline Question & Q1 & Q2 & Q3 & Q4 & Q5 & Q6 & Q7 & Q8 & Q9 \\
\hline $\begin{array}{l}\text { Mean } \\
\text { response }\end{array}$ & 3.8 & 3.8 & 3.5 & 3.3 & 3.7 & 3.7 & 3.8 & 3.9 & 3.4 \\
\hline SD & 0.42 & 0.71 & 0.52 & 0.78 & 0.57 & 0.50 & 0.44 & 0.53 & 0.83 \\
\hline
\end{tabular}




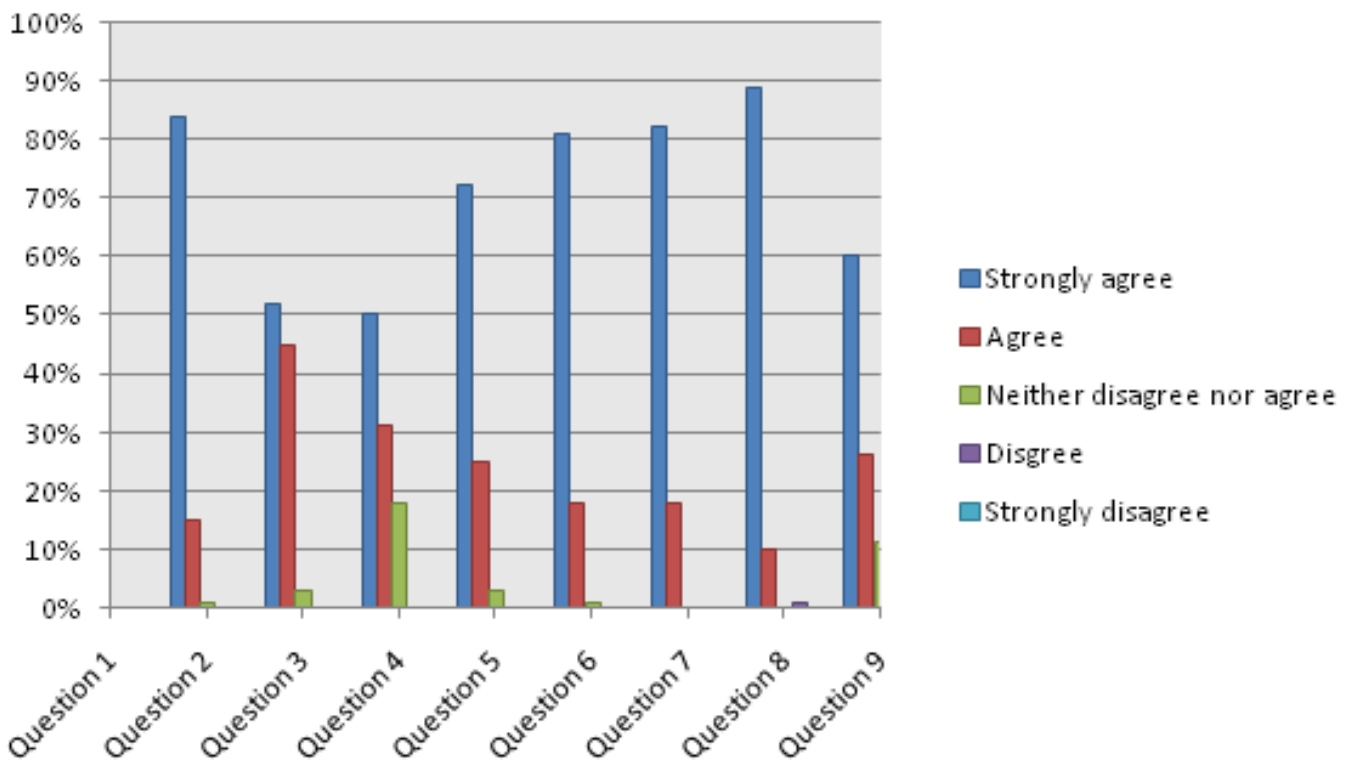

Figure 2. Results of student questionnaire (scale from 0 to 4 ).

All the students felt that the case based metabolic unit learning approach was a good tool for understanding concepts as compared to the classical approach. A majority (97 to $100 \%$ ) of students rated "agree" on a 5 point Likert scale for "well organization and preparation of CBMU", "The significant relevance of the cases to the metabolic pathways of the module", "helping understanding the metabolic pathways of the module","The challenge to think and interact", "the clear \& logical framework of biochemical information in the learning method and highlighting its clinical significance" and $81 \%$ felt that this model "has increased their interest in the field of biochemistry".

When the future application of this approach in learning biochemistry and other basic sciences was asked, $99 \%$ of them recommended applying this method to all biochemistry courses in all modules and $86 \%$ recommended applying it to other basic science subjects. "Overall, all students agree that this approach has been effective in advancing their learning in biochemistry".

In response to the open ended question about what did they like in CBMU, mostly, all respondents wrote positive comments as:

1- Interactive method that we have an applied case we work on and analyze, we did not only have a perfect overview about the metabolic pathway in an organized simplified way but we also enjoyed the interaction and the way the lectures were organized. 
2- Much more interesting that it encourages me to open the text book and read more about the topic which I do not do often. I think this the best topic I did understand in biochemistry

3- It made the lecture easier to follow. It is more thought -provoking than the classical approach (i.e. explaining the metabolic pathway then explaining its clinical application). The lecture was more focused, and had a clear aim: understanding the biochemical principles behind the given case

4- I actually liked the CBMU generally, as an overall opinion because it helped me understand biochemistry and less effort at home and I also liked the way the lecture was presented, it has made a brilliant link between the case and the clinical information needs to be studied.

\section{Discussion}

It puzzles medical students that biochemistry is outside the perspective of medicine. This can be solved if medical biochemistry explains how it applies to medicine, sticks with students and diminishes rote memorization.

Integrated teaching affords a holistic approach, whereas the basic tenets of biochemistry should be discussed in the light of the applied and clinical subjects. The major advantage of case based metabolic unit is that it makes biochemistry a harmonizing partner in the integration that is not completely accomplished by the classical approach.

In the CBMU learning approach, we first defined core biochemical concepts that teachers and students could review in the locomotor module. We discussed these essential ideas and medical applications of biochemistry deeply, by a series of well planed clinical cases. These patients stories are what make the acquisition of biochemistry knowledge compelling. They serve as the scaffolding on which facts and concepts can be reorganized and reinforced.

CBMU seems to be a good model of learning, on the basis of the current questionnaire results. All of the EMP students sensed that the clinical cases were motivating and reflected that this approach facilitated their understanding and memorization of the metabolic pathway. The improvement in students exam scores ensures that they grasped the knowledge. They were inspired to concentrate on many biochemical concepts. Students enrolled in this module speak out that by the asset of this case-based metabolic unit, they were able to integrate biochemistry basic facts in the form of clinical cases. 
Case Based Metabolic Unit (CBMU): A Model for Better Understanding of Metabolic Pathways in the Second Year Extended Modular Program Medical Students

In support of our data on CBMU, previous reports on case based learning in biochemistry topics [4 and 6] and in health care teaching [7 - 10]. The significance of using interactive discussion of clinical vignettes that highlighted the biochemical basis of various diseases was discussed by Prober and Heath. [11].

Two limitations of applying this learning model: firstly, care should be considered in the case design to reinforce the student's understanding of the core concepts of biochemistry. Secondly, not all biochemistry staff will accept this learning process by taking students through a clinical case due to lack of clinical experience.

However, the feedback of students in the current study encouraged us in using case based metabolic unit as a method of learning, as it had a significant impact on the students. Another outcome is faculty training and development that improves the quality of teaching in the future.

In conclusion CBMU as a learning model of metabolic pathways in EMP integrated curriculum was perceived positively by the students and was reflected on their academic performance. They valued the introduction of clinical cases to solidify the relevance of biochemistry to clinical practice. The major advantage of case based metabolic unit is that it makes biochemistry a harmonizing partner in the integrated curriculum which is not completely accomplished by the classical teaching approach

\section{References}

[1] D'Eon MF. Knowledge loss of medical students on first year basic science courses at the University of Saskatchewan. BMC Med Educ 2006;6:5

[2] Ling Y, Swanson DB, Holtzman K, Bucak SD. Retention of basic science information by senior medical students. Acad Med 2008; 83(Suppl):82-85.

[3] Wilhelmsson N, Bolander-Laksov K, Dahlgren LO, et al. Long-term understanding of basic science knowledge in senior medical students. Int J Med Educ 2013;4:193-197

[4] McRae M. Using Clinical Case Studies to Teach Biochemistry in a Doctoral Program: A Descriptive Paper. Creative Education 2012; 3(7): 1173-1176

[5] Williams A. How to write and analyse a questionnaire. Journal of Orthodontics 2003;30:245-252.

[6] Nair S.P., Shah T, Seth S, Pandit N, and Shah G.V. Case Based Learning: A Method for Better Understanding of Biochemistry in Medical Students. J Clin Diagn Res. 2013; 7(8): 1576-1578.

[7] Schoeman JP, Van Schoor M, van der Merwe LL, Meintjes R.A. A case based small group Co operative learning course in Pre clinical Veterinary Science aimed at bridging basic science and clinical literacy. JS Afr Vet Assoc. 2009;80(1):31-36.

[8] Groves M. Problem based learning and learning approach: is there a relationship? Adv Health Sci Edu. 2005;10:315-26.

[9] Ghosh Sarmishtha. Combination of didactic lectures and case oriented problem solving tutorials toward better learning: perceptions of students from a conventional medical curriculum. Adv Physiol

Educ.2007;31(2):193-97. 
Case Based Metabolic Unit (CBMU): A Model for Better Understanding of Metabolic Pathways in the Second Year Extended Modular Program Medical Students

[10] McLean, S.F.(2016) A case based learning and its application in medical and health care fields: A review of worldwide literature. Journal of Medical Education and Curricular Development .3,39-49

[11] Prober CG and Heath C. Lecture halls without lectures--a proposal for medical education. N Engl J Med. 2012 May 3;366(18):1657-9.

\section{Acknowledgments}

We sincerely thank our EMP students for their participation in this study. 
Case Based Metabolic Unit (CBMU): A Model for Better Understanding of Metabolic Pathways in the Second Year Extended Modular Program Medical Students

Appendix A. Case based metabolic unit.

\section{Case Scenario:}

A 35 -year-old man had a lifelong history of exercise intolerance that was often accompanied by episodes of cramping. He described a sensation of his legs becoming stiff like a board after walking for a while and was relieved by rest. The episodes were somewhat ameliorated by drinking sucrose-rich soft drinks immediately before exercise.

The latest episode occurred during his first spin class in the Gym. He initially had extreme weakness in both legs, muscle cramps and later excreted red brown urine.

\section{Investigations:}

- Sensory nerve test conduction showed normal findings.

- Serum lactate level before forearm ischemic exercise test: $10 \mathrm{mg} / \mathrm{dL}$, after test 10 $\mathrm{mg} / \mathrm{dL}$.( $\mathrm{N}$ : increase in lactate post test)

- $\mathrm{CK}: 5,000 \mathrm{IU} / \mathrm{L}$ at rest (N:60 - 400IU/L), and 35,000 IU/L with muscle exertion

- LDH: 400 (N:105-230 U/L)

- Serum myoglobin:671 ng/ml (N:0 - $85 \mathrm{ng} / \mathrm{mL})$.

- Urine myoglobin: positive ( $\mathrm{N}$; negative) ( a colored cup of urine photo is presented with the case)

- Random blood sugar $110 \mathrm{mg} / \mathrm{dl}$ (N: up to $140 \mathrm{mg} / \mathrm{dl}$ )

- A muscle biopsy specimen stained for glycogen showed subsarcolemmal accumulation of "lakes" of glycogen (a colored histopathological photo is presented with the case).

- Results of enzyme histochemistery performed on the muscle biopsy showed negative myophosphorylase enzyme

- Genetic testing: homozygous mutation in PYGM (Myophosphorylase) gene diagnostic of McArdle's disease 
Case Based Metabolic Unit (CBMU): A Model for Better Understanding of Metabolic Pathways in the Second Year Extended Modular Program Medical Students

Appendix B. Case questions and learning objectives:

Case Questions

1. Describe patient' complains?

2. What are significant findings in patient's investigations?

\section{Learning objectives:}

1. Define glycogen?

2. Describe glycogen structure?

3. What is the importance of glycogen for muscle?

4. How is glycogen formed in muscle?

5. What is the relation between glycogen and the type of muscular exercise?

6. What are energy systems for muscular exercise?

7. Why were patient's complaints improved by drinking sucrose drinks before exercise?

8. Why were serum CK, LDH myoglobin increased?

9. Why was not lactate increased in post-forearm ischemic exercise test?

10. Why was urine reddish brown in color?

11. Why was there subsarcolemmal accumulation of glycogen in muscle biopsy?

12. What is myophosphorylase? What is the significance of its absence in muscle biopsy?

13. What is the relation between PYGM mutation and the disease? 
Case Based Metabolic Unit (CBMU): A Model for Better Understanding of Metabolic Pathways in the Second Year Extended Modular Program Medical Students

Appendix C. Student questionnaire: perception of students on case based metabolic unit

Please give your opinion for each of the following objectives regarding your experience of learning biochemistry using a new learning method "Case Based Metabolic Unit" in the locomotor module.

Q1) The learning method was well organized and prepared

Q2)The case presented was significantly relevant to biochemistry content of the module.

Q3)This method challenges me to think and interact

Q4)This method has increased my interest in the field of biochemistry

Q5) It helped me understand biochemistry

Q6) In this method, the biochemical information was following a clear \& logical framework highlighting its clinical significance.

Q7) Overall, this method has been effective in advancing my learning in biochemistry.

Q8) I recommend applying this method to all biochemistry courses.

Q9) I recommend applying this method to other subjects

Q10) What do you like about this learning method? Please write

\section{Likert scale:}

0 : strongly disagree, 1 : disagree, 2: neither agree nor disagree, 3 : agree, 4: strongly agree 